\title{
CORE DESIGN STUDY FOR A SMALL MODULAR BOILING WATER REACTOR
}

\author{
Andhika Feri Wibisono and Eugene Shwageraus \\ University of Cambridge \\ Department of Engineering, University of Cambridge, CB2 1PZ Cambridge, United Kingdom \\ afw36@cam.ac.uk, es607@,cam.ac.uk
}

\begin{abstract}
The hybrid Small Modular Boiling Water Reactor (SMBWR) is a new conceptual design of BWR-type SMR. The main features of SMBWR include a natural circulation loop in its coolant recirculation system and external superheaters system integrated into the steam cycle. A full core analysis of SMBWR is performed with the nodal diffusion code PANTHER using homogenised constant libraries generated by WIMS. The study compared a number of core geometry configurations and fuel management schemes to suppress excess reactivity throughout fuel depletion. Three options for SMBWR core aspect ratio using the same power density are investigated with the aim to assess the effect on the neutronic and thermalhydraulic performance of the SMBWR. It is found that the thin and tall core configuration (192 fuel assemblies and $3.60 \mathrm{~m}$ ) showed the least favourable performance out of the three options as it has the largest core pressure drop and thus requires taller chimney to develop natural circulation.
\end{abstract}

KEYWORDS: Small Modular Boiling Water Reactor, full core analysis, excess reactivity, moderator temperature variation.

\section{INTRODUCTION}

In order to transition from the current energy supply towards low-carbon technology, the trade-off between sustainability, energy security and affordability has to be taken into consideration. The path forward lies between two alternatives, reducing the storage costs for the intermittent renewables or developing an affordable and more flexible nuclear power. One of the possible solutions proposed for the latter path is by developing a Small Modular Boiling Water Reactor (SMBWR) combined with external superheater [1]. The SMBWR was designed to adopt natural circulation of coolant within the reactor vessel during normal operation. By adopting natural circulation, the recirculation pumps could be eliminated from the vessel, thus, able to remove some of the RPV penetrations below the core. By having the external superheaters integrated into the SMBWR, the power conversion cycle efficiency of SMBWR would be improved, which means more electric power could be generated, thus improving the economics of the reactor. Furthermore, it offers the possibility for the SMBWR to reduce its load only by adjusting the external heat supplied to the superheaters, operating the reactor at full power all the time and improving its economics. In addition, by adding superheaters, the SMBWR would no longer need steam dryers, further reducing the vessel height.

The scope of this work is to identify the effect of core dimensions (active fuel length and number of fuel assemblies) on the performance of SMBWR. As the core dimensions for SMRs are smaller, the system 
becomes more sensitive to leakage. Therefore, the trade-off between neutron leakage (neutronics), chimney height requirement for natural circulation (thermal hydraulics), and dimension of the core and vessel which would affect the manufacturing and transportation complexity are interesting subjects to investigate. In terms of neutronics, a thin and tall core would have high radial leakage, while a wide and short core would have high axial leakage. In terms of loop thermal hydraulics, a different core height means different pressure drop across the core. Thus, the requirement for driving head to develop natural circulation would be different. Three core configurations, with variation of length to diameter ratio, are investigated in this study by keeping a constant core power density, coolant mass flow rate and inlet conditions. The reference fuel assembly adopted in this study was the GE14 BWR design, which is used in both Advanced Boiling Water Reactor (ABWR) and Economic Simplified Boiling Water Reactor (ESBWR).

\section{METHODOLOGY}

The tools used to perform the neutronic analysis in this work were WIMS and PANTHER. WIMS [2] is a modular software package for fuel assembly lattice neutron transport calculations. WIMS was used as a lattice code to generate homogenised constants libraries for PANTHER [3], a nodal diffusion code which includes a thermal-hydraulic feedback. WIMS has been proven to accurately model the neutronic behaviour of PWR core. The resonance self-shielding calculation in WIMS uses the equivalence theory approach, with subgroup treatment for $\mathrm{U}^{235}$ and $\mathrm{U}^{238}$, and the Method of Characteristics (MOC) is used to obtain the neutron transport equation solution. PANTHER is originally developed to model the whole core performance of PWR and Advanced Gas-cooled Reactor (AGR) in the UK. Since the capability of modelling BWRs has only been recently added to the codes, a benchmark study of the WIMS package with continuous energy Monte Carlo reactor physics code Serpent [4] was carried out to gain confidence in the model. A 2D-assembly benchmarking of WIMS and Serpent was done using the fuel assembly configuration shown in Fig. 1 for 3 different historical coolant densities. The fuel assembly model is depleted with the same burnup mesh in both WIMS and Serpent and the result is displayed in Fig. 2. By comparing the behaviour of reactivity with burnup predicted by WIMS and Serpent for the 2D-assembly, some discrepancies can be observed between the two codes especially in the beginning of life which become smaller with the burnup. This behaviour suggests that the possible cause of this discrepancy is related to the differences in modelling Gadolinium depletion between the two codes.

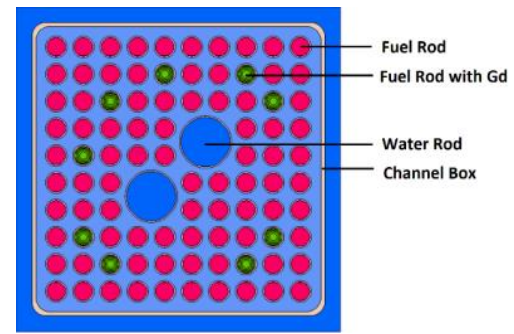

Figure 1. BWR Fuel Assembly Configuration.

In a 3D-assembly benchmark, it is important to note that the fuel burnup in a specific node in the core is accumulated under operating conditions that could be significantly different from the core average values. This is especially important for BWRs since the coolant density changes drastically as it flows through the reactor core channels. It is therefore important to account for the local spectral history effect in modelling BWR assembly. The cross-section data library is generated in WIMS by depleting the fuel with 3 historical coolant densities and a set of instantaneous branches for each one, in order to account for the local spectral history effect. The perturbed cases for the cross-section data library branches include 3 different fuel temperatures, 5 different coolant densities, and 2 coolant temperatures. Another method which could be 
used for better capturing the spectral history effect is the microscopic depletion method. The method accounts for the spectral history effect by calculating the actual concentrations of important nuclides in each node and explicitly adding their contributions to the homogenised macroscopic absorption and fission crosssections [5]. Fig. 3 shows the difference between depletion behaviour of the $2 \times 2$ cluster of 3 -dimensional SMBWR fuel assemblies modelled with Serpent and PANTHER. It could be observed from Fig. 3 that the combination of multiple historical densities and microscopic depletion helps in reducing the discrepancies between the 3D-model simulation in Serpent and PANTHER. The fact that the combination of WIMSPANTHER with historical densities and microscopic depletion is able to reproduce the behaviour of the BWR fuel assembly over burnup as Serpent suggest that the neutronic modelling tools have sufficient accuracy for the purposes of this study.

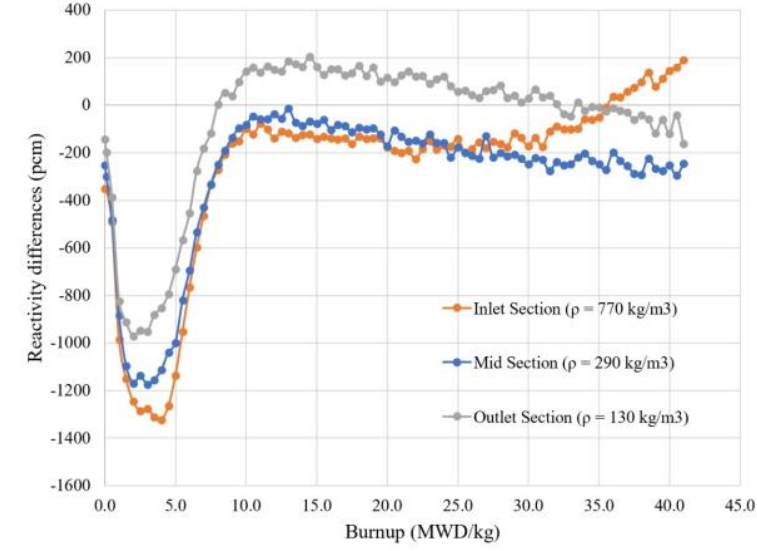

(a)

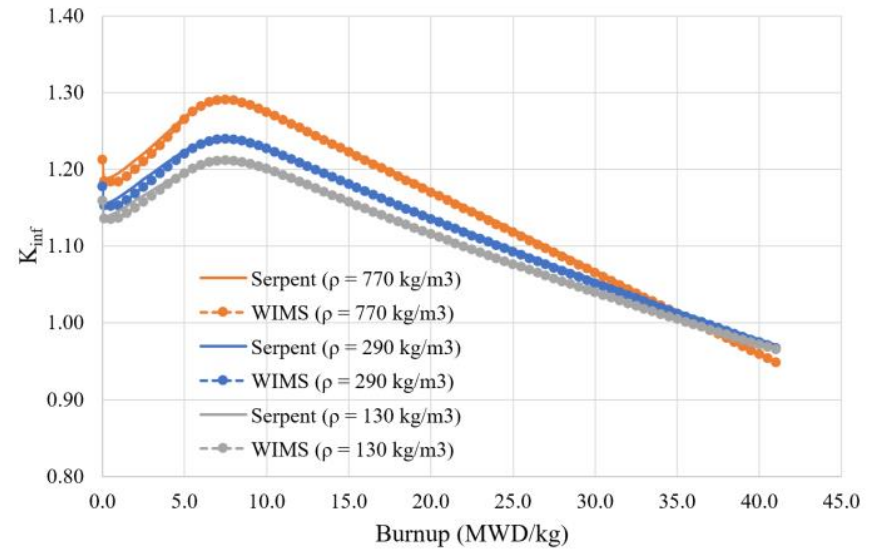

(b)

Figure 2. Benchmark 2D-Assembly Level of WIMS vs Serpent: (a) Reactivity Differences; (b) kinfinity.

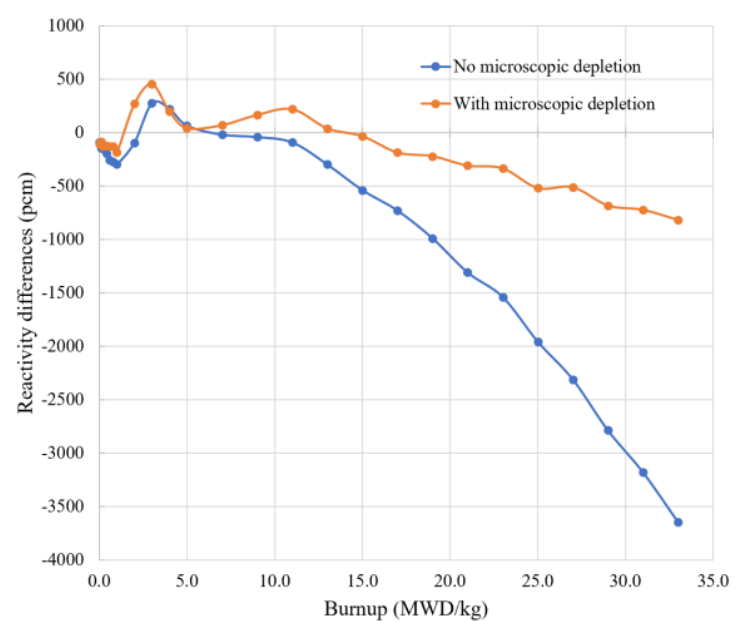

Figure 3. Benchmark 3D-Assembly Level of PANTHER vs Serpent.

For thermal hydraulics analysis, both COBRA-EN code [6] was used as well as a natural circulation loop model developed for this analysis. The natural circulation loop was modelled by calculating the pressure losses contributing to each component in the primary coolant loop. The details of the model including the equations used to calculate the pressure losses in both single-phase and two-phase flow can be found in [1] 
and will not be repeated here. The two-phase flow model implemented in the loop analysis is based on a drift flux model, where the void fraction is calculated by Armand-Treschev correlation [7]. After calculating the pressure drop in all components in a BWR recirculation loop and solving the momentum balance analytically, the model searches for the minimum required height for the system to be able to sustain natural circulation. The core thermal hydraulic performance was modelled with COBRA-EN which is a subchannel analysis developed specifically for this purpose. Fig. 4 shows the core axial void distribution for ESBWR calculated by both the loop model and COBRA-EN compared to the reference value [8]. It is demonstrated in Fig. 4 that the core void distribution of ESBWR modelled by COBRA-EN reasonably closely agrees with the reference value, while the loop model shows a small discrepancy compared to the reference value. The difference in the predicted core pressure drop between COBRA-EN and the loop model is approximately $1.7 \mathrm{kPa}(2.30 \%)$ which is small and quite negligible. This is another reason why COBRA$\mathrm{EN}$ is used to perform the channel analysis inside the core. Although the core void distribution predicted by the loop model shows small discrepancy with the reference value, it predicts a similar trend and core exit void fraction predicted by the loop model is close to the reference value. The observed discrepancies are most likely due to void fraction prediction model used in the core. Therefore, the fact that the pressure drop calculation does not show significant difference to COBRA-EN result and that the core is only one component of the circulation loop where the heat source is generated, provide confidence that the loop model for solving the momentum balance in the SMBWR vessel has sufficient accuracy for the purposes of this study.

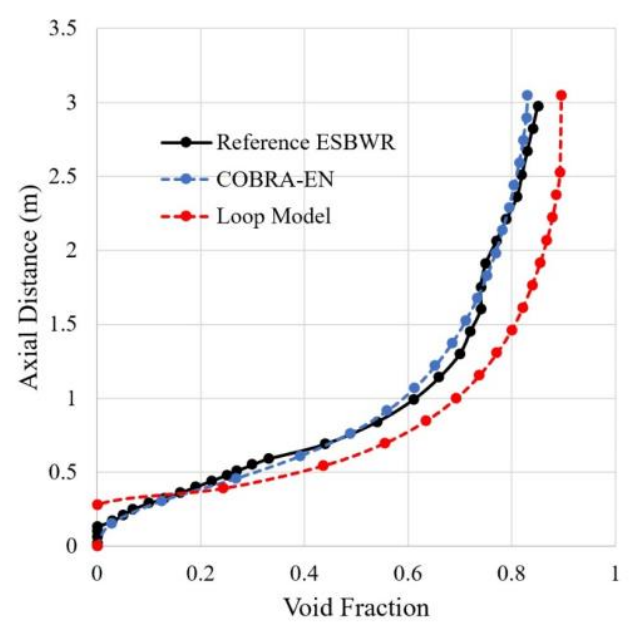

Figure 4. Comparison of The Thermal Hydraulic Models in Capturing ESBWR Core Void Distribution.

\section{COMPARATIVE STUDY ON CORE GEOMETRY}

One of the objectives of the study is to quantify the effect of the core dimensions on the performance of SMBWR. The dimensions would affect the trade-offs between neutron leakage (neutronics), chimney height requirement for natural circulation (thermal hydraulics), and dimensions of the vessel which would determine the manufacturing and transportation difficulty. For this purpose, three different geometry configurations, with different length to diameter ratios are selected for the study. This section compares the neutronic and thermal hydraulic performance of three different core geometries, as specified in Table I. In designing BWR core, the hydrogen to heavy metal ratio is an important parameter, as it is related to the core average void fraction. The nominal H/HM of all GE-Hitachi designs have been around 4 for an average void fraction of $40 \%$. Therefore, this value is used as the design parameter in all the cases in this study. Case 1 is representative of a thin and tall shape (192 fuel assemblies with fuel active length of $3.6 \mathrm{~m}$ ), while 
Case 3 has a wide and short shape (368 fuel assemblies with fuel active length of $1.88 \mathrm{~m}$ ). Thus, it is expected that Case 3 will have higher axial neutron leakage through the top and bottom of the core, while Case 1 will have higher radial leakage. The core average power density was kept constant in all three considered geometries. The neutronic study is performed with axially uniform enrichment of $4.2 \mathrm{wt}-\% \mathrm{U}^{235}$, nine of the fuel pins contain Gadolinia poison $\left(\mathrm{Gd}_{2} \mathrm{O}_{3}\right)$ with the concentration of $2 \mathrm{wt}-\%$. No axial fuel zoning has been used at this stage of the study, as the main objective was a high-level comparison of the neutronic performance of 3 selected core configurations. Fig. 5 displays the multiplication factor of the full core model using 3-batch fuel arrangement. Fig. 6 shows the depletion behaviour of the core reactivity feedbacks in a single-batch configuration, while Fig. 7 shows the core reactivity feedbacks over burnup for a 3-batch core.

Table I. Core geometry specification.

\begin{tabular}{|l|c|c|c|}
\hline \multirow{2}{*}{ Parameter } & \multicolumn{3}{c|}{ Geometrical Variation } \\
\cline { 2 - 4 } & $\mathbf{1}$ & $\mathbf{2}$ & $\mathbf{3}$ \\
\hline No. of fuel assemblies & 192 & 256 & 368 \\
\hline Power density (kW/L) & 48.2 & 48.2 & 48.2 \\
\hline Active fuel length (m) & 3.60 & 2.70 & 1.88 \\
\hline Shroud diameter (m) & 2.60 & 2.90 & 3.52 \\
\hline
\end{tabular}

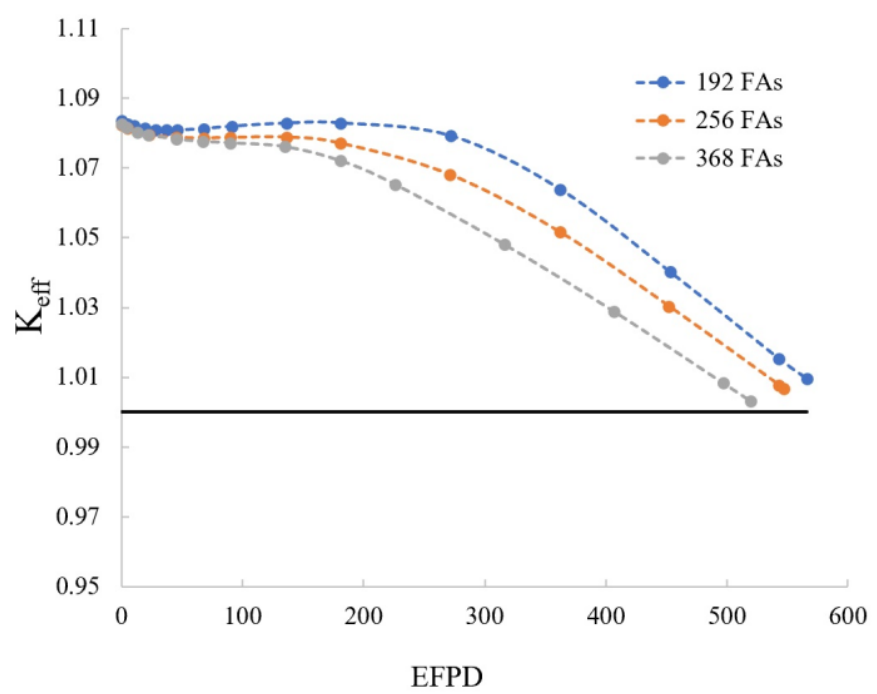

Figure 5. Comparison of The Multiplication Factor for The Studied Geometries.

Fig. 5 shows that in 3-batch arrangement, the neutron economy of Case 3 is slightly more inferior due to leakage compared to the other two configurations. Since the three core configuration cases have the same thermal power, the core with larger number of fuel assemblies will have shorter fuel active length, and thus, higher axial neutron leakage. Fig. 6 shows that the shape of the core has notable effect on the core reactivity feedbacks. In terms of Doppler coefficient, the presence of gadolinium poison causes the Doppler Coefficient to be more negative. It can be seen from Fig. 6 that at the beginning of life (BOL), Case 3 has slightly less negative Doppler Coefficient (DC). The increase in leakage hardens the spectrum, increases the resonance absorption, and thus increasing DC. In addition, by having higher leakage, the plutonium build-up in Case 3 is higher than the other 2 cases, which is the reason for the shift in DC in Case 3 to become slightly more negative at the end of life (EOL) compared to the other cases. It can be seen from 
Fig. 7 that by having 3-batch configuration, the Doppler coefficient becomes less dependent on burnup and no significant differences are observed between the studied geometries over the cycle. The loading pattern arrangement used in cases presented in Fig. 7 are shown in Fig. 8. The assembly type denoted " 0 " in Fig. 8 represents fresh fuel assembly, while types 1, 2, and 3 represent once, twice, and thrice burnt fuel, respectively, and $\mathrm{R}$ represents reflector. In terms of CVC, it is known that this reactivity feedback tends to become more negative at the EOL due to plutonium build-up and overall depletion of fissile material. However, the presence of gadolinium poison alters this behaviour at the BOL. It can be observed that 3batch configuration helps reducing the variation in the CVC throughout the cycle in all studied geometries.

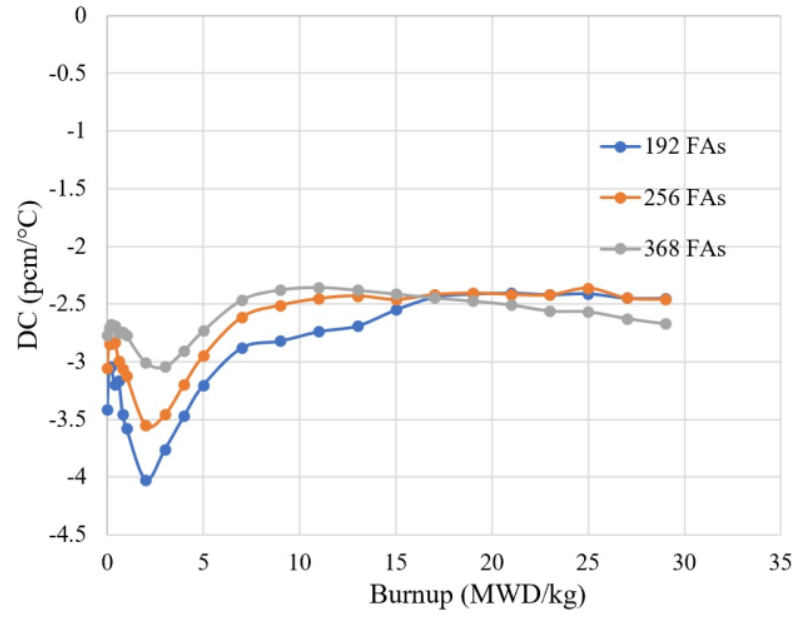

(a)

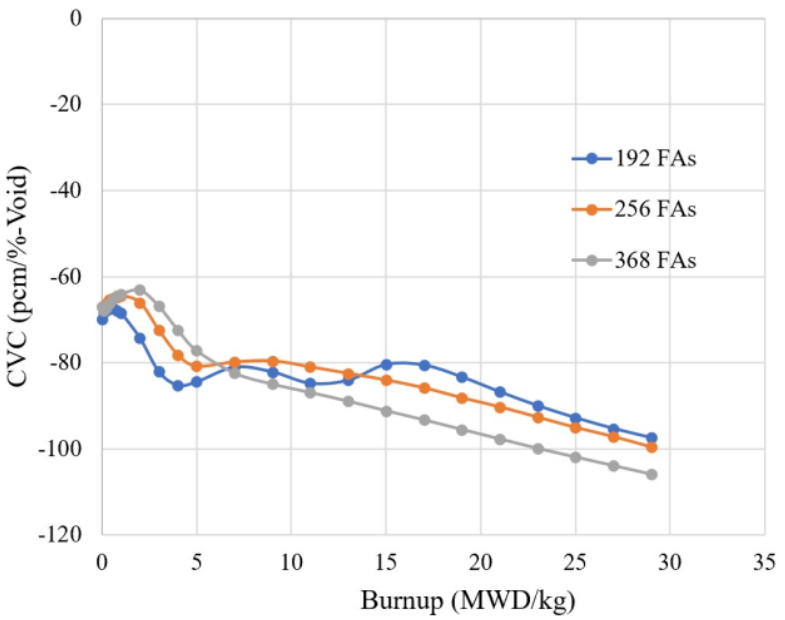

(b)

Figure 6. Depletion Behaviour of Reactivity Feedbacks for the Studied Geometries: (a) Doppler Coefficient; (b) Coolant Void Coefficient.

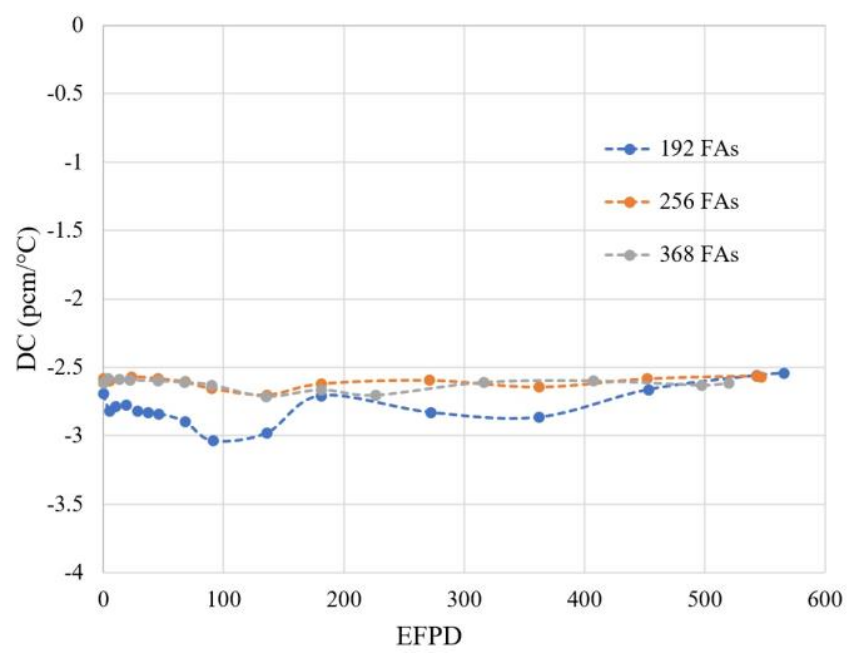

(a)

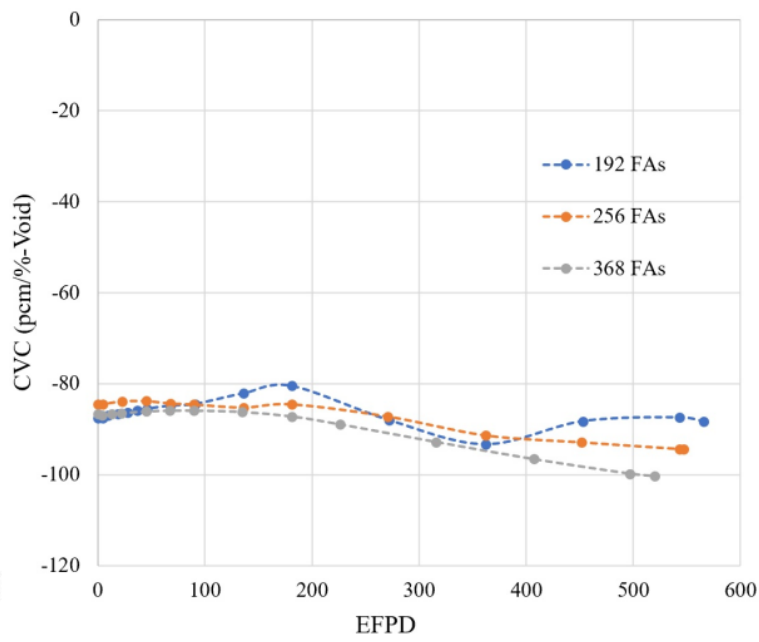

(b)

Figure 7. Reactivity Feedbacks Comparison for The Studied Geometries with 3-Batch Arrangement: (a) Doppler Coefficient; (b) Coolant Void Coefficient.

As the natural circulation was chosen to be one of the design requirements for SMBWR, a fair comparison of the core geometries would have to include a study on core pressure losses and the required height for the 
chimney to develop natural circulation. The core axial void distribution and axial density profile at MOL are shown in Fig. 9 while Table II summarises the design parameters of the three compared cases. In order to estimate the dimension of the reactor vessel as shown in Table II, the height of other components in the vessel (lower plenum, upper plenum, and dome) are conservatively assumed to be the same as those of ESBWR. It was found that a taller core has higher core pressure losses, and thus, requires a taller chimney to develop natural circulation. In terms of thermal hydraulics, another important parameter is the Minimum Critical Power Ratio (MCPR) as the main indicator of safety in a BWR. The MCPR is known to be the most important BWR thermal limit. COBRA-EN has a number of methods of calculating critical power. The one selected for this study is proposed by General Electric [9] and known as the GEXL correlation. The GEXL correlation is a variation of the critical quality vs boiling length correlation and is based on experimental data obtained for the pressure range of 55-100 bar [9]. Since the GEXL correlation is developed and recommended by GE for their standard fuel geometry, it is appropriate to be used in this analysis which also uses a GE standard assembly design as a reference. It was found that Case 1, which is the tallest option of all three geometries studied has the lowest MCPR value. The likely reason for that could be the fact that a taller core would have a higher mass flux. This higher mass flux is correlated to higher assembly power. Although critical power also increases with higher mass flux, the ratio between critical power to assembly power would become smaller.

\begin{tabular}{|lllllllll|}
\hline 2 & 2 & 0 & 0 & 2 & 2 & 1 & 1 & $\mathrm{R}$ \\
2 & 2 & 0 & 0 & 2 & 2 & 1 & 1 & $\mathrm{R}$ \\
0 & 0 & 2 & 2 & 1 & 1 & 0 & $\mathrm{R}$ & $\mathrm{R}$ \\
0 & 0 & 2 & 2 & 1 & 1 & 0 & $\mathrm{R}$ & \\
2 & 2 & 1 & 1 & 0 & 0 & $\mathrm{R}$ & $\mathrm{R}$ & \\
2 & 2 & 1 & 1 & 0 & 0 & $\mathrm{R}$ & & \\
1 & 1 & 0 & 0 & $\mathrm{R}$ & $\mathrm{R}$ & $\mathrm{R}$ & & \\
1 & 1 & $\mathrm{R}$ & $\mathrm{R}$ & $\mathrm{R}$ & & & & \\
$\mathrm{R}$ & $\mathrm{R}$ & $\mathrm{R}$ & & & & & & \\
\hline
\end{tabular}

(a)

\begin{tabular}{|c|c|c|c|c|c|c|c|c|c|c|c|c|c|c|c|c|c|c|c|c|c|}
\hline 0 & 1 & 1 & 0 & 0 & 1 & 1 & 2 & 2 & $\mathrm{R}$ & 0 & & & 0 & 0 & 2 & 2 & 1 & 1 & 0 & 0 & \\
\hline 1 & 3 & 3 & 2 & 2 & 0 & 0 & 1 & 1 & R & & 2 & & 1 & 1 & 0 & 0 & 2 & 2 & 1 & 1 & \\
\hline 1 & 3 & 3 & 2 & 2 & 0 & 0 & 1 & 1 & $R$ & & 2 & & 1 & 1 & 0 & 0 & 2 & 2 & 1 & 1 & \\
\hline 0 & 2 & 2 & 1 & 1 & $?$ & 2 & 0 & & & 0 & 1 & 1 & 3 & 3 & 2 & 2 & 1 & 1 & 0 & $\mathrm{R}$ & \\
\hline & & & 1 & & & & 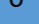 & $n$ & $k$ & 0 & 1 & 1 & 3 & 3 & 2 & 2 & 1 & 1 & 0 & $\mathrm{R}$ & \\
\hline 0 & 2 & 2 & 1 & 1 & 2 & 2 & 0 & $\mathrm{R}$ & & 2 & 0 & 0 & 2 & 2 & 2 & 2 & 0 & 0 & $R$ & $\mathrm{R}$ & \\
\hline 1 & 0 & 0 & 2 & 2 & 0 & 0 & $\mathrm{R}$ & $\mathrm{R}$ & & 2 & 0 & 0 . & 2 & 2 & 2 & 2 & 0 & $\mathrm{R}$ & $\mathrm{R}$ & & \\
\hline 1 & 0 & 0 & 2 & 2 & 0 & $\mathrm{R}$ & $\mathrm{R}$ & & & 1 & 2 & 2 & 1 & 1 & 0 & 0 & 0 & R & & & \\
\hline 2 & 1 & 1 & 0 & 0 & $\mathrm{R}$ & $\mathrm{R}$ & & & & 1 & 2 & 2 & 1 & 1 & 0 & $\mathrm{R}$ & $\mathrm{R}$ & $\mathrm{R}$ & & & \\
\hline 2 & 1 & 1 & $\mathrm{R}$ & $R$ & $R$ & & & & & 0 & 1 & 1 & 0 & 0 & $\mathrm{R}$ & $\mathrm{R}$ & & & & & \\
\hline $\mathrm{R}$ & $R$ & $\mathrm{R}$ & $R$ & & & & & & & 0 & 1 & 1 & $\mathrm{R}$ & R & $\mathrm{R}$ & & & & & & \\
\hline & & & & & & & & & & $\mathrm{R}$ & & R & R & & & & & & & & \\
\hline
\end{tabular}

(b)

(c)

Figure 8. Loading Pattern Configuration for Multi-Batch Arrangement: (a) 192 FAs; (b) 256 FAs; (c) 368 FAs.

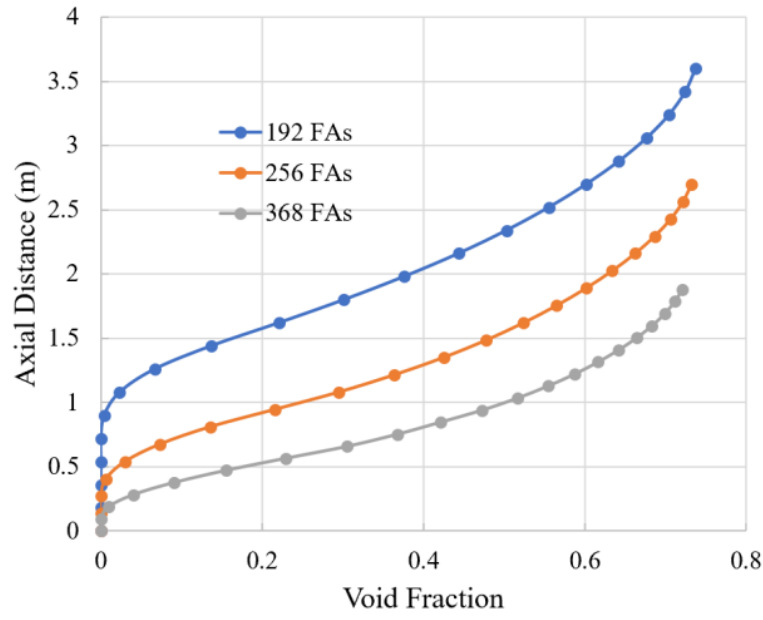

(a)

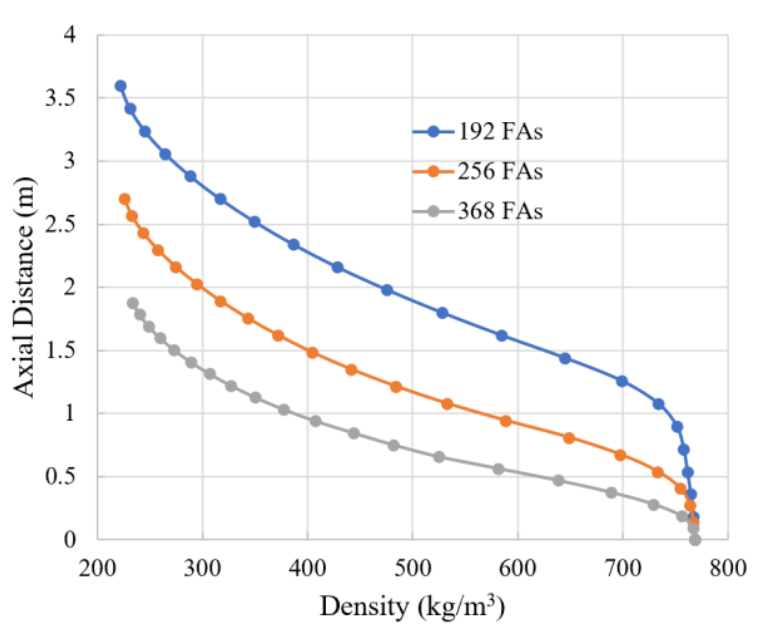

(b)

Figure 9. Core Axial Profile at MOL: (a) Void Fraction; (b) Density. 


\section{CONCLUSIONS}

The comparative study of SMBWR core geometry found that the least favourably performing core design out of the three considered design options is Case 1 which is the tallest core and with fewest fuel assemblies (192 fuel assemblies and fuel length of $3.60 \mathrm{~m}$ ). It is shown that the thin and tall core configuration requires taller chimney to ensure natural circulation. In addition, this core configuration will have the lowest MCPR margin. Furthermore, this configuration also has the most variation in the behaviour of the reactivity feedbacks throughout the fuel depletion. Case 3 (368 fuel assemblies and fuel length of $1.88 \mathrm{~m}$ ) has the lowest pressure drop, highest safety margin (highest value of MCPR), and the most stable behaviour of the reactivity feedbacks throughout the fuel depletion compared to the other core designs. However, having a wider core would also mean having larger reactor vessel diameter, which might not be the most economic option when considering the manufacturing and construction cost of the NPP.

Table II. Thermal hydraulic performance comparison for the studied geometries.

\begin{tabular}{|l|c|c|c|}
\hline \multirow{2}{*}{ Parameter } & \multicolumn{3}{c|}{ Geometrical Variation } \\
\cline { 2 - 4 } & $\mathbf{1}$ & $\mathbf{2}$ & $\mathbf{3}$ \\
\hline No. of fuel assemblies & 192 & 256 & 368 \\
\hline Power density $(\mathrm{kW} / \mathrm{L})$ & 48.2 & 48.2 & 48.2 \\
\hline Active fuel length $(\mathrm{m})$ & 3.60 & 2.70 & 1.88 \\
\hline Shroud inlet diameter $(\mathrm{m})$ & 2.60 & 2.90 & 3.52 \\
\hline Core length to diameter ratio & 1.47 & 1.01 & 0.60 \\
\hline Estimated vessel diameter $(\mathrm{m})$ & 3.71 & 3.94 & 4.44 \\
\hline Operating pressure $(\mathrm{MPa})$ & 7.17 & 7.17 & 7.17 \\
\hline Feedwater inlet temperature $\left({ }^{\circ} \mathrm{C}\right)$ & 192 & 192 & 192 \\
\hline Core inlet temperature $\left({ }^{\circ} \mathrm{C}\right)$ & 273 & 273 & 273 \\
\hline Core average void & 0.32 & 0.36 & 0.40 \\
\hline Core mass flow rate $(\mathrm{kg} / \mathrm{s})$ & 2414.3 & 2414.3 & 2414.3 \\
\hline Core pressure drop $(\mathrm{kPa})$ & 63.58 & 50.70 & 42.33 \\
\hline Minimum required height of chimney $(\mathrm{m})$ & 4.84 & 3.58 & 3.09 \\
\hline Estimated vessel height $(\mathrm{m})$ & 18.5 & 16.3 & 15.2 \\
\hline MCPR & 1.47 & 1.56 & 1.65 \\
\hline
\end{tabular}

SMRs development strategy relies on the assumption that their components could be produced in a factory, then transported and assembled on site. Having a large diameter vessel would complicate manufacturing and transportation of the vessel, which may affect the capital costs of the NPPs. According to European Commission and UK transportation regulations, the low loader lorries, a means of road transport for an abnormally large and heavy loads, have maximum width limitation of $4.3 \mathrm{~m} \mathrm{[10].} \mathrm{This} \mathrm{suggests} \mathrm{that} \mathrm{the}$ Case 3 estimated vessel diameter has surpassed the specification limit of the road transport. In addition, it is also found that in terms of neutronics, Case 3 is the least efficient design as it has larger surface to volume ratio with high axial neutron leakage. Therefore, the next stage of this study will focus on Case 2 of the core design (256 fuel assemblies and fuel length of $2.70 \mathrm{~m}$ ), as it offers a compromise between the neutronics, thermal hydraulics and RPV manufacturing and transport considerations. 


\section{REFERENCES}

1. A.F. Wibisono, J.I. Lee, E. Shwageraus, "Effect of operating pressure on the performance of a hybrid system of small modular boiling water reactor with external superheaters," Nuclear Engineering and Design, 353 (2019).

2. ANSWERS, "WIMS - A Modular Scheme for Neutronics Calculations," User Guide for Version 10, The ANSWERS Software Package, ANSWERS/WIMS/REPORT/014, ANSWERS, UK (2015).

3. A. Morrison, "PANTHER User guide," Technical report, British Energy, Barnwood, UK (2003).

4. J. Leppanen, "Serpent -a Continuous-energy Monte Carlo Reactor Physics Burnup Calculation Code," User's Manual, VTT Technical Research Centre of Finland (2015).

5. Y. Bilodid, D. Kotlyar, E. Shwageraus, E. Fridman, and S. Kliem, "Hybrid microscopic depletion model in nodal code DYN3D," Annals of Nuclear Energy, 92, pp. 397-406 (2016).

6. D. Basile, R. Chierici, M. Beghi, E. Salina, and E. Brega, "COBRA-EN - an Upgraded Version of COBRA-3C/MIT Code for Thermal-Hydraulic Transient Analysis of Light Water Reactor Fuel Assemblies and Cores," COBRA-EN User's Manual (1999).

7. A. A. Armand and G. G. Treschev, "Investigation of the Resistance during the Movement of SteamWater Mixtures in Heated Boiler Pipe at High Pressures," AERE Lib/Trans., 81 (1959).

8. GE Hitachi Nuclear Energy, "ESBWR Design Control Document Tier 2," Revision 10, GE-Hitachi Nuclear Energy Americas LLC, USA (2014).

9. General Electric, "GENERAL ELECTRIC BWR THERMAL ANALYSIS BASIS (GETAB): DATA, CORRELATION AND DESIGN APPLICATION," Technical report, NEDO-10958-A, California, USA (1977).

10. R. P. McDonnell, "Transport Strategy for Small Modular Reactors," MPhil Dissertation, University of Cambridge, Cambridge, UK (2017). 